feminist unity and global inequities, the potential and difficulties for women's political mobilization on a local and international scale. Sessions on poverty, employment, and reproductive rights all claimed attention, but overall it was clear that no single issue and no single language of feminism sufficed or predominated.

The plenary on women in Ireland was a telling illustration of this diversity of outlooks. The reformist optimism, the universalizing and unifying good will of the keynote parliamentary speakers Mary Robinson and Monica Barnes as well as historian Margaret MacCurtain was abruptly contradicted by Ursula Barry, a feminist sociologist and activist, who insisted on the harsher realities and conflicts of Irish life (poverty, unemployment, emigration, sexual violence, homophobia) connecting the contemporary feminist struggle to an anti-imperialist analysis that clearly disquieted her colleagues, while the same analysis and her acerbic wit delighted the audience. Not coincidentally Irish media coverage ignored her contribution to this session and generally treated the conference as a bizarre jamboree.

The relationship of national and international communities was constantly invoked, highlighting the simultaneous specificity and interconnectedness of our feminisms and oppressions. Questions raised by discussions of the part played by women in national liberation struggles and the role of women in the "shrinking" global factory, teased out the different analyses (or lack of analysis) amongst feminists in attendance and gave a welcome reminder to the majority of U.S. feminists that women's studies is indeed intensely political and that our preoccupations must be with the structural, systemic nature of class, race, and gender oppressions.

The Fourth International Interdisciplinary Congress on Women will be held in 1990 at Hunter College in New York City. The venue is significant: the future in this city seems particularly bleak for women. The organizers promise more attention to organization, particularly fundraising and advertising, to enable greater non-U.S. participation. It remains to be seen how our agendas-feminist, political, and academic - will have developed by then and how tensions and preoccupations inherent in the experience of Dublin in 1987 will be played out.

\title{
Custom and Commerce in Early Industrial Europe
}

\author{
Edward Countryman
}

University of Warwick

This conference, held at the Center for the Study of Social History at the University of Warwick, in Coventry, April 24-26, 1987, was sponsored by the Economic and Social Research Council (ESRC) Working Group on Proto-Industrial Communities as the centerpiece of a series of symposia. Approximately fifty people took part, and the seventeen presenters represented nine different countries. 
Five sessions were held over three days. The first, "The Market and the State," was chaired by Eckart Schremmer (Heidelberg) and attracted papers by Sidney Pollard (Bielegeld), James Thomson (Sussex), and Edward Countryman (University of Warwick). The second session was "Merchants, Middlemen, and Market Structures." The chair was Louis Bergeron (Paris), and papers were given by Brenda Collins (Belfast), Stanley Chapman (Nottingham), Toshio Kusamitsu (Tokyo), and Jaime Torras (Barcelona). Franklin Mendels (Geneva) chaired the third session, "Manufacture and the City." Among those presenting papers were Paul Hohenberg (Rensselaer Polytechnic Institute), Maxine Berg (University of Warwick), Michael Sonenscher (Middlesex Polytechnic), and Martha Howell (Rutgers University). The fourth session, "Agrarian Custom and Common Rights," included papers by Franco Ramella (Turin), Jeanette Neeson (Queen's University, Ontario), and Pat Hudson (Liverpool) and was chaired by Christopher Smout (St. Andrews). Gywynne Lewis (University of Warwick) chaired the last session, "Artisans and Market Culture," with papers by William Reddy (Duke University), Lars Magnusson (Uppsala), and Gay Gullickson (University of Maryland).

As the presence of Mendels, Hohenberg, and Schremmer suggests, a good deal of the discussion concentrated on the problem of protoindustrialization as an organizing concept. The conference ranged widely, however, both in geographical terms and in mode of approach. The papers by Pollard, Hohenberg, and Reddy were broadly interpretive, but most of the others focused tightly on specific communities (Neeson on common rights in Northamptonshire; Collins on sewing outwork in Ulster; Thomson and Torras on eighteenth-century Spain) and problems (Magnusson on drinking and custom in nineteenth-century Ekilstuna, Sweden; Gullickson and Howells on women; Kusamitsu on fashion and novelty in the organization of British industry).

A volume is planned by the conference organizers, John Davis (University of Warwick) and Maxine Berg (University of Warwick).

\title{
Fifteenth Annual Conference of the Western Society for French History
}

\author{
Edgar Leon Newman \\ New Mexico State University
}

Food and song were the principal subjects of the fifteenth annual conference of the Western Society for French History, held at Las Cruces, October 28-November 1, 1987, in conjunction with the centennial of New Mexico State University. The main banquet, an elegant dinner prepared by Jacques Pépin called "French Cooking through the Eighties - the 1680s, the 1780s, the 1880s, and the 1980s," featured one 